\title{
Framework for airfield pavements management—an approach based on cost-effectiveness analysis
}

\author{
Muhammad Irfan $^{1} \cdot$ Muhammad Bilal Khurshid $^{2} \cdot$ Shahid Iqbal $^{1} \cdot$ Abid Khan $^{2}$
}

Received: 1 June 2014 / Accepted: 29 March 2015 / Published online: 11 April 2015

(C) The Author(s) 2015. This article is published with open access at SpringerLink.com

\begin{abstract}
Purpose and research question The agencies responsible to operate and maintain airfields in developing countries manage the airfield pavements on need to do/ reactive basis instead of resorting to performance based preventive maintenance and rehabilitation (M\&R) activity profiles. Extracting due cognizance from literature on internationally recognized airfield pavements management systems, this research article presents a framework of the step-wise procedure for airfield pavement management system.

Methods M\&R effectiveness is quantified based upon area bounded by the pavement performance curve and cost is the present worth of total cost incurred by the agency. The evaluation and prioritization of different alternatives is based on life cycle cost analysis and cost effectiveness index. The case study for an in-service airfield has also been presented to demonstrate the application of proposed methodology.

Results The evaluated M\&R alternatives for a given preservation scenario include: Joint Filling, Patching and 2" thick overlay; Milling and 2" thick AC overlay of mid-section (keel) section; Replacement with complete 4" thick AC Overlay;
\end{abstract}

Muhammad Irfan

mirfan@mce.nust.edu.pk

Muhammad Bilal Khurshid

mbilal@nit.nust.edu.pk

Shahid Iqbal

dean@mce.nust.edu.pk

Abid Khan

kabid12764@yahoo.com

1 Military College of Engineering (MCE), National University of Sciences \& Technology (NUST), Risalpur 24080, Pakistan

2 National Institute of Transportation (NIT), School of Civil \& Environmental Engineering (SCEE), National University of Sciences and Technology (NUST), Islamabad 44000, Pakistan and Re-construction of complete airfield. The analysis results revealed that Mill and 2" thick AC overlay of mid-section was the most cost effective alternative entailing minimum cost while yielding maximum benefit pavement performance. Conclusions The developed pavement management process provides systematic and objective procedures for maintaining the inventory of pavement infrastructure, monitoring pavement performance, selecting optimal treatment and its application time. The proposed management system for the airfield pavements will not only prioritize the areas for repair/ maintenance but also give a cost-effective solution for enhancing the airfield pavement service life..

Keywords Decision support systems $\cdot$ Life cycle costs . Maintenance $\cdot$ Pavement management $\cdot$ Rehabilitation · Statistical models

\section{Introduction}

Airfields pavements require huge investment of public funds for construction and subsequent maintenance purpose. These pavements are the backbone of the essential economic activities i.e. transporting goods and persons not only in industrialized societies but also in developing countries. The increase in air traffic has subjected these pavements to more loads than the past and has effected these pavement structures which are either approaching or have exhausted their design life. Due to this deterioration, the airfield management agencies have gradually shifted their emphasis from construction of new pavements to maintenance and rehabilitation (M\&R) of existing ones. Managing an aging pavement network is difficult due to the complex behavior of pavement. Also the growing budgetary constraints, under which most agencies are now forced to fiscal parsimony, have caused reduction in maintenance 
activities. In the last two decades, research proclivity has been towards the development of airfield pavement management systems (APMS) by many agencies. The major role of these systems is assisting decision-makers to find M\&R strategies for maintaining airfield pavements in a serviceable condition over a specified time period in the most cost-effective manner [1]. Depending on the preferences of the agency/ organization concerned, APMSs may take various forms, however all APMSs have some common elements/ functions, necessary for operation. These important functions are network inventory, pavement condition evaluation, pavement performance prediction and planning methods. An APMS facilitates life cycle cost analysis (LCCA) for various alternatives and aids in decision-making about the timing of applying the best alternative. It provides a systematic, consistent method for selecting M\&R needs and determining priorities and the optimal time of repair by predicting future pavement condition [2]. It is a valuable tool that alerts the pavement manager about a critical point (or a trigger) for the application of appropriate treatment (preventive maintenance (PM) or rehabilitation) in a pavement's life cycle as shown in Fig. 1, which indicates that the repair costs may be reduced considerably, if M\&R is performed during the early stages of deterioration, before the pavement reaches the minimum level of serviceability (threshold performance level) and needs complete reconstruction. Threshold performance level or trigger value is the minimum acceptable performance level below which the pavement is considered to be unacceptable for its designated function. These are often based on agency's performance standards and/or user perspectives. Often, agencies seek to utilize threshold values that are performance-based rather than time-based. The short term effectiveness include pavement performance jump (Fig. 1) and is useful in simulations of pavement performance and compare effectiveness between alternative treatments, whereas longterm effectiveness include service life extension, average pavement performance and area bounded by the performance curve and are appropriate for major preservation treatments, compared to minor treatments and useful for preservation "strategies" or "schedules" i.e., combinations of different treatment types and timings over asset life cycle or remaining life and it also compare effectiveness of different preservation strategies as shown in Fig. 1.

Currently in Pakistan, airfields maintenance and rehabilitation decisions are based on historical practices / experience of airfield engineers and discretion of administrative authorities with no emphasis on life cycle cost analysis and other management practices. In the present environment of fiscal parsimony, the pavement infrastructure requires a more systematic and methodical approach for determining M\&R needs and priorities. Mostly agencies in the country make decisions about pavement M\&R based on instant needs or experience rather than long-term planning or documented data. This approach did not allow the country's management agencies to evaluate the cost effectiveness of alternative maintenance and repair strategies, which resulted in an inefficient use of funds. Recent developments in airfield pavement management provide a way forward in managing pavements timely and economically. This research paper describes in detail an airfield pavement management system for use at airfields in Pakistan that will ensure examining the existing $M \& R$ practices and develop a framework for economical and effective expenditure of maintenance funds commensurate with the functional requirements and the planned future use of the facilities. The research study describes a stepwise procedure starting from pavement inventory followed by inspections/ distress survey, pavement performance evaluations and selection of $M \& R$ strategies. This will enable the airfield management agencies to prioritize the airfields pavements requiring M\&R through judicious allocation of the available budget. In an effort to throw more light on the issue, this paper uses historical condition data and activity profile of in-service airfield pavements and compare it with application of proposed APMS using various sample feasible $M \& R$ alternatives.

\section{An appraisal of existing airfield pavement management systems}

Airfield pavement management system started in 1970s through a research conducted by Construction Engineering
Fig. 1 Typical pavement life cycle M\&R strategies and performance curve

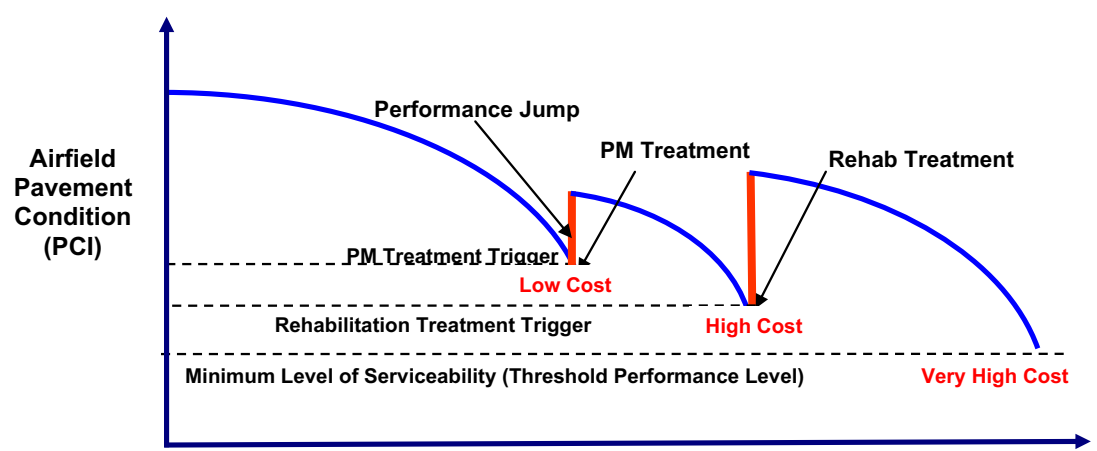

Airfield Pavement Age, $t$ 
Research Laboratory (CERL) for US Air Force. This research managed to established PAVER and MicroPAVER management Systems to devise a system that prioritizes the budget for the Air Force bases as per their requirement (MicroPAVER [3]). The latest version of the system also includes the Foreign Object Damage (FOD) Index and structural analysis for carrying out the residual life analysis. McNerney and Harrison [4] conducted an analysis of various APMSs and concluded that the MicroPAVER was merely based on surface distress, and was time consuming system that did not take into account the airline and airfield costs such as costs for user delays as a result of closed runways, increased roughness causing fatigue to aircraft. An Enhanced APMS (EAMPS), later developed, addressed the complete economic impact of pavement network that includes aircraft delay and operating costs (ARA [5]). Broten and Wade [6] carried out a systematic assessment and analysis of airport pavement management practices by conducting a survey of all states of US aviation agencies. Several state transportation agencies, notably Michigan, Minnesota, Ohio and California also developed comprehensive pavement maintenance guidelines in their respective areas of jurisdiction (MDOT [7]; MNDOT [8]; ODOT [9]; CalTrans [10]). U.S. Department of Defense issued Unified Facilities Criteria (UFC) publications, relevant reports and technical manuals on pavement maintenance management [11]. In addition to above systems which are applicable to both flexible and rigid airfield pavements other APMSs that are specific to pavement type are also available e.g., AirPACS has been developed to solve different problems related to rehabilitation of jointed plain concrete pavement (JPCP) airfield pavements [12].

The main elements of all these APMSs include the network inventory, different methods to evaluate and rate the condition of pavements, approaches used for predicting the evaluation of pavement condition over time and lastly the planning methods. The condition surveys are expressed in the form of a quality index e.g. pavement condition index (PCI) corresponding to a single or combination of different pavement characteristics and represent the deterioration state of pavement at a given time [13]. The PCI procedure forces the collection of a large data regarding various distresses for computing the overall index. The drawback in the PCI method is the dubious repeatability of visual surveys due to the subjective nature and difference between the severities of distresses, which can be controlled by extensive and meticulous inspection guidelines or by the use of automated data collection devices [14]. In addition to the functional evaluations, the design and evaluation procedures of airfield pavements are based on structural considerations such as limiting stresses, strains and deflections [15]. The structural evaluation constitutes determining the physical properties of the pavement materials e.g., California Bearing Ratio (CBR), modulus of elasticity $(\mathrm{E})$, sub-grade reaction modulus $(\mathrm{K})$ etc. and then assessing the deformation response by examining the loading effects. In case of airfield pavements, Non-destructive testing (NDT) using heavy weight deflectometer (HWD) is useful because it generates much higher loadings than the actual aircraft loadings. In addition, ground penetrating radar and infrared thermal photography are specifically useful in locating voids under the pavement surface [16]. The NDTs enables airfield managing agencies to conduct frequent surveys of their pavements' structural capacity and provides them with a basis for decision-making. In APMSs, various performance prediction models are critical elements that control important management decisions. Pavement performance serves as a tool in the planning of future M\&R actions and can be predicted through two types of models i.e., deterministic and probabilistic $[17,18]$. Functional performance models are PCI prediction models that have mostly been developed for PAVER system and are also used in other APMSs such as Integrated APMS and AirPAVE (FAA [2,19]). The models built for performance prediction relate the future PCI value to a series of explanatory or predictive variables such as the age of pavement, time since last overlay, structural integrity (deflection measurement) and traffic, etc. Structural performance models relate the materials characteristics of the pavement structure and the loads applied to it for determining the number of cycles of load applications before the occurrence of failure. Such type of prediction models are widely used by pavement managers and have been developed for pavements by various organizations i.e. Portland Cement Association (PCA), Asphalt Institute, U.S Army Corps of Engineers and Shell International Petroleum Company ([15]; Zaniewshi [20]).

The decision-making and planning include determining the M\&R actions that should be taken by the managing agency keeping in view the current and predicted pavement condition within its jurisdiction and the budgetary resources/ constraints. Life cycle cost analysis for a given section or project analyzes possible $M \& R$ alternatives that are expected to provide the required performance in the pavement section and to identify the most cost effective one over the analysis period. The most advanced method for optimizing the allocation of available funding used by transportation agencies is the multi-year prioritization using incremental cost-effectiveness analysis, but is seldom implemented for airport pavement networks. The reasons for slower implementation include smaller airport pavement networks, greater importance of operational issues at airports, and limitations of existing airport pavement management software (ACRP [21]).

The appraisal of existing studies on APMSs contains only a limited selection from the available information, with the objective to provide an overview of common airport pavement maintenance practices and their current application. Taking due cognizance of available literature, this research study customizes a framework for APMS that provides guidance for 
distress survey, monitoring pavement performance, quantifying benefits and cost analyses, scheduling maintenance and rehabilitation (M\&R) based on cost-effectiveness analysis of asphalt concrete (AC) and Portland cement concrete (PCC) airfields.

\section{Study methodology}

The stepwise procedure of the developed framework is presented in Fig. 2. The framework includes an airfield pavement management procedure based on the evaluation of distress data, rate of deterioration, and other direct measurements such as skid potential and profile roughness. Guidelines for identifying different feasible M\&R alternatives established on the results of the evaluation are also presented. Finally the selection of the optimum M\&R alternative is based on economic analysis, pavement agency's mission and management policies. The ensuing sections explain the complete process for an airfield pavement management system.

\subsection{Inventory / Data Collection}

For initiation of any management system the airfields pavements must be divided into various components like branches, sections and sample units. An airfield's pavement network branches consists of all surfaced areas that provide access to ground or air traffic e.g., runways, taxiways, aprons, roads and storage areas. A section is a division of a particular branch with certain consistent characteristics/ attributes throughout its area/ length including: structural composition (thickness and materials); construction history; traffic; and pavement condition.
Fig. 2 Developed framework of proposed airfield pavement management system

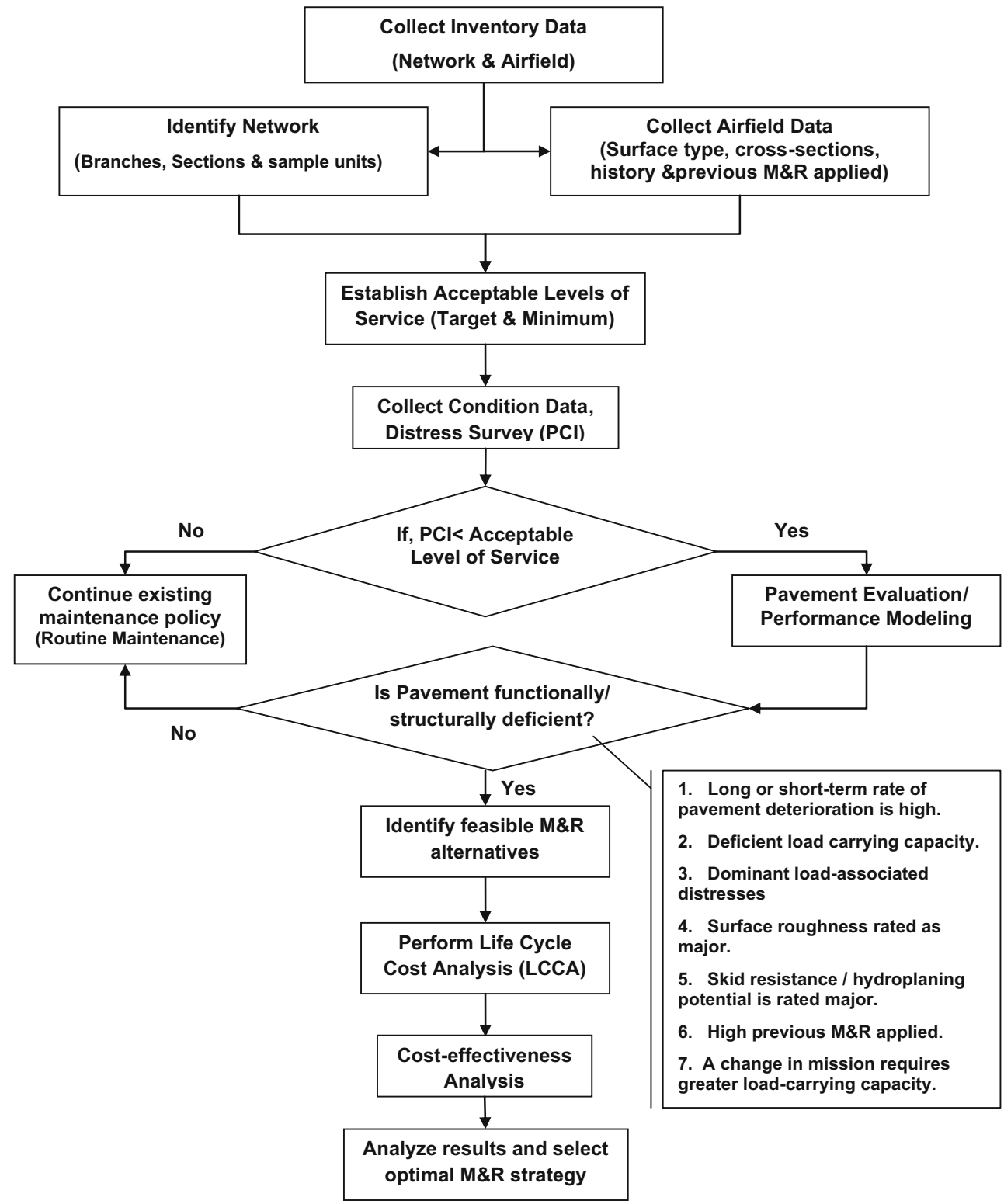


A sample unit is the smallest component of any airfield pavement network and is an area within a pavement section obtained by dividing sections into sample units. Inspecting an entire section requires considerable effort, especially if the section is a large one. A statistical sampling plan is therefore developed to obtain an adequate PCI. The inspection is carried out on a portion of the sample units within that particular section i.e., $20 \pm 8$ slabs for rigid pavements, and 5,000 \pm 2 , 000 square feet for flexible [22]. The statistical sampling plan described herein will considerably reduce the time required to inspect a section without significant loss of accuracy. Assuming a normal distribution of data, the number of sample units to be surveyed having $95 \%$ confidence level can be determined using Eq. (1):

$\mathrm{n}=\mathrm{N} \sigma^{2} /\left(\mathrm{e}^{2} / 4(\mathrm{~N}-1)+\sigma^{2}\right)$

Where

$\mathrm{n}$ number of sample units to be inspected

$\mathrm{N}$ total number of sample units in feature

$\sigma$ standard deviation in PCI between sample units within the feature (10 and 15 for flexible and rigid pavements, respectively)

e allowable error in determining the true PCI

Airfield data The extent and types of maintenance previously applied to a pavement section must be determined before selecting a new strategy. Following data is compiled for subsequent use during the condition survey: design/ construction/ maintenance history; air traffic history (including aircraft type, typical gross loads, frequency of operation, runway usage, taxiway and apron usage); climatic/meteorological data (including frost action, etc.), airfield layout plans including photographs, pavement condition survey reports.

Pavement functional and structural evaluation Examining the distresses present in a pavement section help in identifying the cause of pavement deterioration, its extent and eventually its M\&R needs. In addition, the effect of drainage on distress occurrence is also investigated because moisture has considerable effect on the rate of distress occurrence. Also, the drive through inspection checks is conducted for any FOD, whereas the quarterly inspection report records the complete pavement inventory and any other abnormality on the airfield. Minor, moderate, or major surface roughness is determined by riding profilers over the pavement section at its speed limit and observing its relative riding quality. Distresses that can cause skid resistance / hydroplaning potential for runways include bleeding, polished aggregates, rutting, and depression (for asphalt pavements) and polished aggregate (for concrete pavements) also need to be surveyed. The load carrying capacity of an airfield pavement is defined in terms of pavement classification number (PCN) which shows the strength of pavement and ensure that pavement is not subjected to excessive wear. The load-carrying capacity depends on the pavement structure and material properties including sub-grade soil properties. The load-carrying capacity of airfield pavements can be determined using different destructive methods developed by FAA and U.S. Army Corps of Engineers. The Non-destructive testing methods and criteria using falling weight deflectometer (FWD) or heavy weight deflectometer (HWD)for evaluating the load-carrying capacity of airfield pavements are used to assess the structural capacity of pavement without any cores or destruction in a quick time [22].

\subsection{Pavement performance prediction}

Pavement deterioration over the years is estimated through pavement performance models [21, 23]. Knowledge of the performance trend subsequent to each treatment application is helpful in M\&R strategy optimization because it enables an estimation of the time when the next maintenance, rehabilitation or reconstruction treatment would be needed. Deterioration of a pavement section depends upon local factors such as the type and number of traffic loadings, environmental conditions, and subgrade strength including drainage and material characteristics. The selection of pavement performance models depends on data availability and other agency requirements to estimate future pavement preservation needs. Understanding the treatment-specific performance model is helpful in M\&R strategy optimization in estimating the time when the next maintenance, rehabilitation, or reconstruction would be needed, and therefore can facilitate the development of realistic schedules and budgets for long-term pavement preservation. The general functional form of post-treatment performance trend for airfield pavements considered in this research study is given in Eq. (2) [23]:

$\mathrm{PI}=\mathrm{f}(\mathrm{t})$

Where: $\mathrm{PI}=$ Performance indicator $(\mathrm{PCI})$ in a given year, $\mathrm{t}$; (PCI is calculated by subtracting total deduct value which is in turn a function of accumulated effect of distress levels and extents expressed as a numerical index between 0 and 100 which is used to indicate the general condition of a pavement. The steps involved in pavement condition evaluations are illustrated in Fig. 3); $f(t)=$ Function of pavement intervention age, $t$ (or a surrogate of age, such as accumulated aircraft traffic loads and/ or climatic effects, etc.)

Airfield pavement performance trend on application of different treatments generally, is a function of load characteristics, type of intervention (applied treatment), climatic effects, moisture and other variable factors. As an example the need for performance prediction and the rate of deterioration for different treatments is illustrated in Fig. 4, which shows 
Fig. 3 Steps involved in pavement condition evaluations

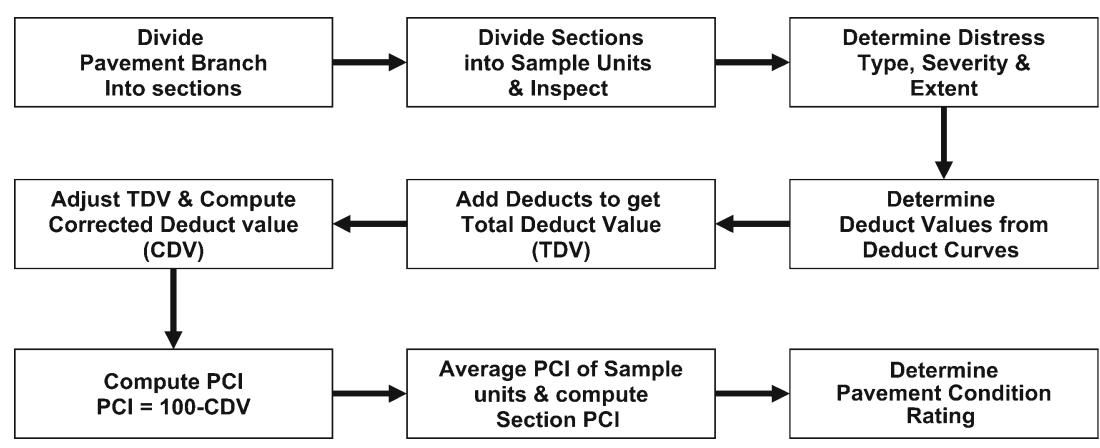

pavement performance trend curves for two pavements. Both pavements have same initial PCI but pavement $B$ deteriorates at a faster rate than pavement $\mathrm{A}$, thus pavement $\mathrm{B}$ will require an earlier pavement preservation treatment than pavement $\mathrm{A}$. As pavement condition reaches a minimum acceptable service level the pavement requires maintenance or rehabilitation. Feedback on the alternatives applied can be judged by monitoring the performance over the years. Figure 1 illustrates the concept of sudden elevation of pavement performance upon treatment (short-term effectiveness) and deterioration trend subsequent to the treatment application (long-term effectiveness). Performance models enable tracking of pavement performance over the life-cycle and are therefore a vital input of the treatment effectiveness perspective. The remaining service life is used to calculate the salvage value of pavement while carrying out the economic analysis and also, is an indicator of the overall condition of the network [24]. The remaining service life for pavement $B$ is ' 2 ' years and that for pavement $A$ is ' 5 ' years as illustrated in Fig. 4.

\subsection{Identification of preservation needs}

The establishment of the minimum acceptable levels of service also provides rational justification for pavement maintenance and rehabilitation needs. Whenever the predicted pavement condition falls lower than the recommended/ target level of service the need for pavement preservation arises. Khurshid et al.[25]) developed a framework for establishing optimal performance thresholds for highway asset interventions. Treatment specific trigger levels relate to application of preservation treatments at the right time within a specified range to be effective, before the PCI falls below the level where the pavement condition require different and more expensive treatment e.g., cracks sealing in AC pavements is most effective when the pavement is still in a good condition. For the purpose of this research, the existing established performance standards developed by airport cooperative research program sponsored by Federal Aviation Administration (FAA) were adopted (Table 1) for selecting the application thresholds for various M\&R treatments (ACRP [21]).

\subsection{Quantifying the benefits of preservation treatments}

The concept of area bounded by post- treatment performance curve integrates the measures of effectiveness (MOEs) of service life and increase in average asset performance and is consistent with the rationale that superior average performance over a longer period provides more benefits compared to inferior performance over a shorter period (Lamptey [26]). For the non-increasing performance indicators, such as PCI this effectiveness is the area under the curve (AUC) (Fig. 5). The benefits of a well-maintained airfield pavement are
Fig. 4 Pavement performance curve for different treatments (Adapted from ACRP [21])

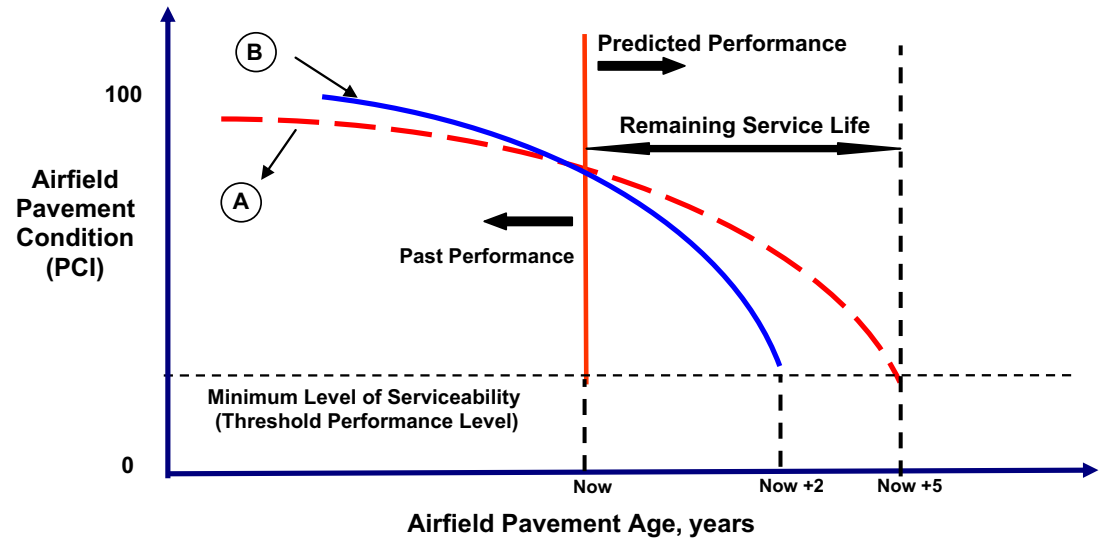


Table 1 Pavement Performance Standards for Airport Pavements (ACRP [21])

\begin{tabular}{lll}
\hline $\begin{array}{l}\text { Pavement Condition } \\
\text { Index (PCI) }\end{array}$ & Performance description & Applicable pavement preservation treatments \\
\hline $86-100$ & Good — only minor distresses & Routine maintenance only \\
$71-85$ & Satisfactory-low and medium distresses & Preventive maintenance \\
$56-70$ & Fair-some distresses are severe & Preventive maintenance and rehabilitation \\
$41-55$ & Poor-severity of some of the distresses cancause operational problems & Rehabilitation or reconstruction \\
$26-40$ & Very poor-severe distresses cause operational problems & Rehabilitation and reconstruction \\
$11-25$ & Serious - many severe distresses cause operational restrictions & Immediate repairs and reconstruction \\
$0-10$ & Failed-pavement deterioration prevents safeaircraft operations & Reconstruction
\end{tabular}

numerous and may be difficult to quantify in monetary terms. In pavement management research, this non-monetized benefit or effectiveness is often expressed in at least one of the three forms: service life extension, average pavement performance and area bounded by the performance curve. The concept of area bounded by the performance curve is considered superior to the others as it embodies the concepts of service life and increased condition. This is consistent with the reasoning that superior average condition for longer periods provides more benefit than inferior condition for shorter periods [23]. The mathematical form of the post treatment-specific area bounded by the performance curve is given in Eq. (3) for the decreasing performance indicator:

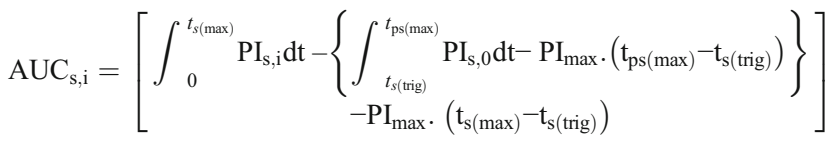

Where
$\mathrm{AUC}_{\mathrm{s}}$
Additional area under the performance curve yielded by treatment, $\mathrm{s}$.
$\mathrm{PI}_{\mathrm{s}, 0} \quad$ Performance model for new construction in terms of performance indicator (PI)

$\mathrm{PI}_{\mathrm{s}, \mathrm{i}} \quad$ Post-treatment performance model for $\mathrm{i}^{\text {th }}$ stage treatment at any year, $\mathrm{t}$

$\mathrm{t}_{\mathrm{s}(\text { trig) }}=\mathrm{t}(\mathrm{i}) \quad$ Actual service life of the $(\mathrm{i}-1)^{\text {th }}$ treatment (the time between the triggering of $\mathrm{i}^{\text {th }}$ treatment and the time when the previous $\left[(\mathrm{i}-1)^{\text {th }}\right]$ treatment was implemented)

$\mathrm{t}_{\mathrm{ps}(\max )} \quad$ Time or age, $\mathrm{t}$ at minimum acceptable performance (serviceability) of pre-treatment (ps)

$t_{s(\max )} \quad$ Time or age, $t$ at minimum acceptable performance (serviceability) of triggered-treatment (s)

A simple calculation of the overall effectiveness of a M\&R strategy comprising multiple treatments following the initial construction is illustrated in Fig. 4 and is given in Eq. (4) for the decreasing performance indicator (PCI):

Effectiveness of $M \& R$ Strategy

$$
=\sum_{\mathrm{s}=1}^{\mathrm{k}} \sum_{\mathrm{i}=0}^{\mathrm{n}} \int_{0}^{\mathrm{t}(\mathrm{i})} \mathrm{PI}_{\mathrm{s}, \mathrm{t}} \mathrm{dt}-\mathrm{PI}_{\max } \cdot \mathrm{t}(\mathrm{i})
$$

Fig. 5 Illustration of quantifying the pavement treatment effectiveness

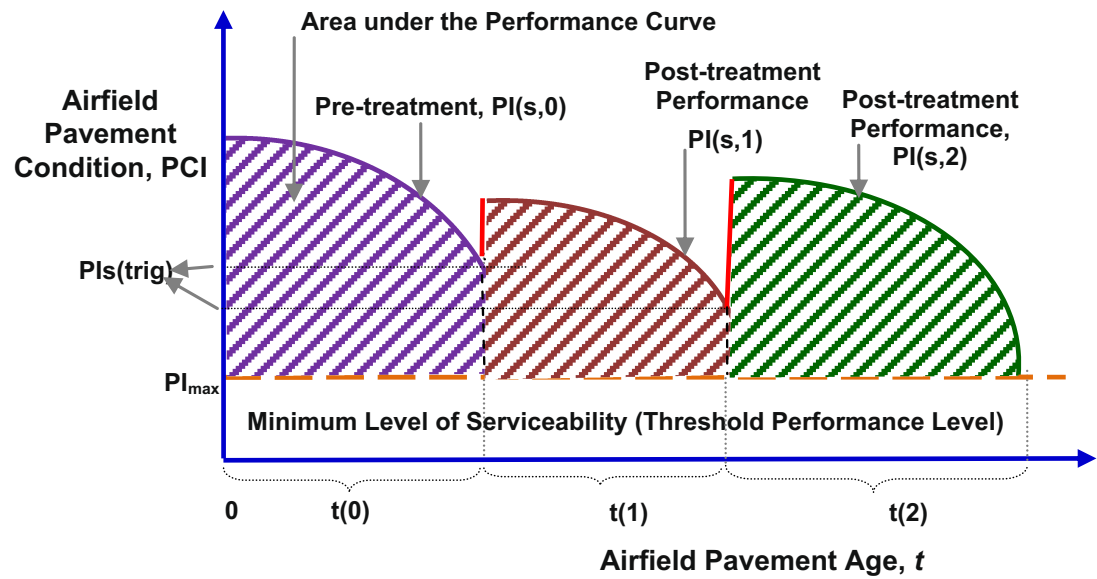


Where

$\mathrm{s}$ the number of alternative M\&R treatments in the given strategy $(s=1,2, \ldots, \mathrm{k})$

i the number of possible triggering stages of treatments (including new construction) in the analysis period $(i=0$, $1,2, \ldots, n)$

All other notations have their usual meaning previously explained.

\subsection{Preservation scenarios and feasible $M \& R$ alternatives}

Literature search revealed a large amount of information available apropos the technology of pavement preservation treatments (ACRP [21]). As such, different agencies could have different customized set of feasible treatments for different preservation scenarios:

Minor Localized (Routine) M\&R Minor localized M\&R includes methods that preserve the condition of the pavement and retard its deterioration. These methods may include crack sealing, joint sealing and application of fog seals and rejuvenators. Minor localized M\&R methods also restore pavement condition e.g., skin patching, applying heat and rolling sand, placing small patches and patching joint and corner spall.

Major Localized (Preventive) M\&R Major localized M\&R includes partial depth or full-depth patching, slab replacement, slab under sealing and slab grinding applied to a larger area or portion of the pavement section. Other major localized M\&R may include application of an aggregate seal over the entire section (micro-surfacing, thin overlays, etc.) in AC pavements and reconstruction of joints in a concrete pavement.

Overall $\mathbf{M} \& \mathbf{R}$ Overall $M \& R$ includes all methods that cover the entire pavement section and improves its structural capacity. Overlays of asphalt (including milling of AC pavements) or PCC overlays, hot \& cold recycling of existing pavements and total reconstruction fall under the category of overall M\&R.

\subsection{Economic analysis of M\&R alternatives}

Selecting the best alternative requires performing an economic analysis to compare the cost-effectiveness of all feasible alternatives [27]. An economic analysis procedure, also called life cycle cost analysis, compares M\&R alternatives using present worth (for equal analysis periods of alternatives: Eq. (5)) or equivalent uniform cost (for varying analysis periods of alternatives). The present worth of any M\&R alternative is the sum of all discounted M\&R costs during the analysis period minus the salvage value discounted to the present. The present worth of all M\&R alternatives is compared with respect to available budget in order to guide the pavement manager in selecting the most suitable alternative.

$\mathrm{PWC}=\mathrm{IC}+\sum_{\mathrm{j}=1}^{\mathrm{k}} \mathrm{M} \& R_{\mathrm{j}} \times[1 /(1+\mathrm{ir})]^{\mathrm{n}_{\mathrm{j}}}-\mathrm{SV}[1 /(1+\mathrm{ir})]^{\mathrm{N}}$

Where:

PWC Present worth of cost of a strategy application

IC Present cost of initial construction or rehabilitation activity

$\mathrm{k} \quad$ Number of future M\&R activities

$M \& R_{j} \quad$ Cost of $j^{\text {th }}$ future M\&R activity in terms of present costs

ir Discount rate

$n_{j} \quad$ Number of years from present to the $j^{\text {th }}$ future M\&R activity

SV Salvage value; and

$\mathrm{N} \quad$ Analysis period length, years

Knowing the benefits and costs of a M\&R strategy, asset managers can compare the overall desirability of alternative treatments or strategies and select the best alternative on the
Fig. 6 Comparison of various activity profiles effectiveness

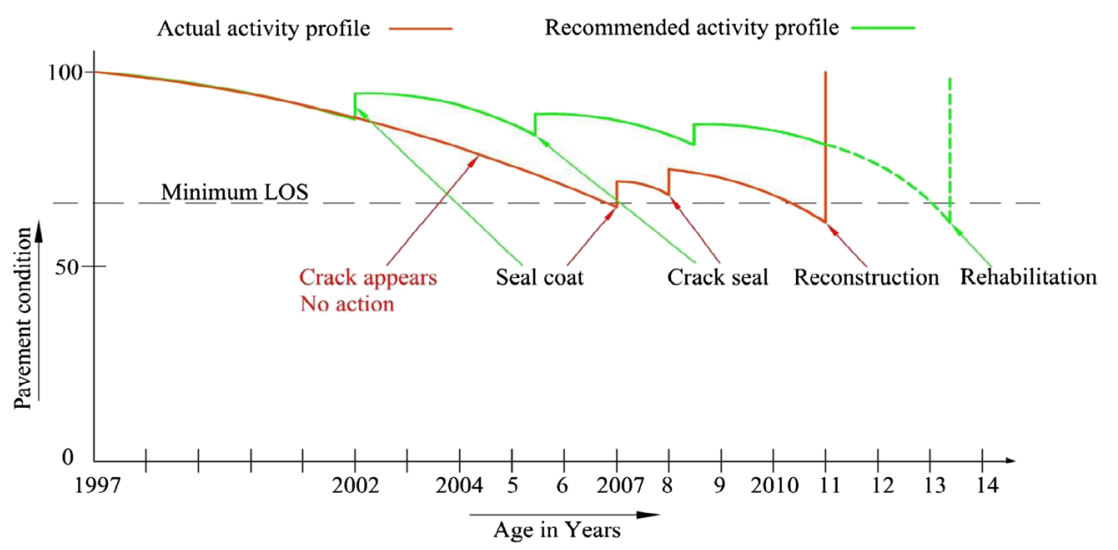


Table 2 Net Present worth of sample feasible M\&R alternatives (a) Patching and apply complete 2" thick overlay

\begin{tabular}{|c|c|c|c|c|c|c|}
\hline Year & Work description & Quantity & Unit cost & Total cost & PWF & Present worth \\
\hline (0) 2011 & Crack Filling & $1274 \mathrm{~m}$ & 198 & $2,52,252$ & 1.000 & $2,52,252$ \\
\hline (0) 2011 & Patching & 570.3 Ton & 5938.3 & $33,86,613$ & 1.000 & $33,86,613$ \\
\hline (0) 2011 & Tack Coat & $125,464 \mathrm{~m}^{2}$ & 41.14 & $51,61,618$ & 1.000 & $51,61,618$ \\
\hline (0) 2011 & 2" AC Overlay & 15,010 Ton & 5938.3 & $8,91,33,883$ & 1.000 & $8,91,33,883$ \\
\hline (5) 2016 & Fog seal & $125,464 \mathrm{~m}^{2}$ & 95.14 & $1,19,36,645$ & 0.822 & $98,11,922$ \\
\hline (8) 2019 & Seal Cracks & $1274 \mathrm{~m}$ & 198 & $2,52,252$ & 0.730 & $1,84,144$ \\
\hline (10) 2021 & Removal of $2 " \mathrm{AC}$ & 6373.7 cum & 855.38 & $54,51,936$ & 0.676 & $36,85,508$ \\
\hline (10) 2021 & Overlay $2 " \mathrm{AC}$ & 15,010 Ton & 5938.3 & $8,91,33,883$ & 0.676 & $6,02,54,505$ \\
\hline (15) 2026 & Fog Seal & $125,464 \mathrm{~m}^{2}$ & 95.14 & $1,19,36,645$ & 0.555 & $66,24,838$ \\
\hline (18) 2029 & Seal Cracks & $1274 \mathrm{~m}$ & 198 & $2,52,252$ & 0.494 & $1,24,612$ \\
\hline SubTotal & & & & & & $17,86,19,895$ \\
\hline Less Salvage Value & & & & & & 0 \\
\hline
\end{tabular}

Net Present Worth

178.62 Million PKR

basis of cost-effectiveness [28]. In an effort to avoid the issues associated with monetization of benefits, a number of past studies resorted to using non-monetized benefits such as the area bounded by the curve, the service life, the decrease in the structural index etc. [28-30]. The cost-effectiveness (CE) Index of each M\&R strategy is calculated using Eq. (6):

Cost Effectiveness $(\mathrm{CE})$ Index $=\frac{\text { Effectiveness (Benefit) }}{\text { PWC }}(6)$

The evaluation and decision-making of optimal M\&R schedule for a given airfield pavement network is made using brute-force enumeration (also referred to generate-and-test) of all feasible alternatives which is proceeded by generating all possible candidate feasible strategies (ARA [5]) randomly followed by determining whether it is a valid solution to the budgetary or the performance constraint.

\section{Applicability of proposed framework - a case study of in-service airfield}

A case study of an in-service airfield is undertaken to perceive the efficacy of the proposed APMS framework. The sampling and data collection plan included the extraction of pavement condition data from annual serviceability reports of selected in-service airfields. The data in the serviceability report provide an information of distress type, its extent and M\&R action taken (if any). However, it doesn't provide other pertinent information needed for APMS regarding distress cause, evaluation procedure, feasible M\&R alternatives and cost effectiveness analysis. The airfield historical data indicates that the runway (RW 16/34) was rehabilitated with 2 " thick Overlay in 1997. The same year is considered as the start point for the activity profile as shown in Fig. 6. The actual activity

Table 3 Net present worth of sample feasible M\&R alternatives (b) Replacement of 2" thick AC Overlay of Keel Section

\begin{tabular}{|c|c|c|c|c|c|c|}
\hline Year & Work description & Quantity & $\begin{array}{l}\text { Unit cost } \\
\text { Rs }\end{array}$ & $\begin{array}{l}\text { Total cost } \\
\text { Rs }\end{array}$ & PW factor & $\begin{array}{l}\text { Present worth } \\
\text { Rs }\end{array}$ \\
\hline (0) 2011 & Removal of 2" AC surface & $2124.6 \mathrm{~m}^{3}$ & 855.38 & $18,17,340$ & 1.000 & $18,17,340$ \\
\hline (0) 2011 & Tack Coat & $41,822 \mathrm{~m}^{2}$ & 41.14 & $17,20,557$ & 1.000 & $17,20,557$ \\
\hline (0) 2011 & 2" AC Overlay & 5004 Ton & 5938.3 & $2,97,15,253$ & 1.000 & $2,97,15,253$ \\
\hline (5) 2016 & Fog seal & $125,464 \mathrm{~m}^{2}$ & 95.14 & $1,19,36,645$ & 0.822 & $98,11,922$ \\
\hline (8) 2019 & Seal Cracks & $1274 \mathrm{~m}$ & 198 & $2,52,252$ & 0.730 & $1,84,144$ \\
\hline (10) 2021 & Tack Coat & $125,464 \mathrm{~m}^{2}$ & 41.14 & $51,61,618$ & 0.676 & $34,89,254$ \\
\hline (10) 2021 & Overlay $2 " \mathrm{AC}$ & 15,010 Ton & 5938.3 & $8,91,33,883$ & 0.676 & $6,02,54,505$ \\
\hline (15) 2026 & Fog Seal & $125,464 \mathrm{~m}^{2}$ & 95.14 & $1,19,36,645$ & 0.555 & $66,24,838$ \\
\hline (18) 2029 & Seal Cracks & $1274 \mathrm{~m}$ & 198 & $2,52,252$ & 0.494 & $1,24,612$ \\
\hline Sub Total & & & & & & $11,37,42,425$ \\
\hline Less Salvage Value & & & & & & 0 \\
\hline Net Present Worth & & & & & & 113.74Million \\
\hline
\end{tabular}

Salvage Value of zero indicates that 2" AC overlay have completed its useful life 
Table 4 Net present worth of sample feasible M\&R alternatives (c) Replacement of Complete 4" thick AC Overlay

\begin{tabular}{|c|c|c|c|c|c|c|}
\hline Year & Work description & Quantity & $\begin{array}{l}\text { Unit cost } \\
\text { Rs }\end{array}$ & $\begin{array}{l}\text { Total cost } \\
\text { Rs }\end{array}$ & PW Factor & $\begin{array}{l}\text { Present worth } \\
\text { Rs }\end{array}$ \\
\hline (0) 2011 & Removal of 4" AC surface & $12,620 \mathrm{~m}^{3}$ & 855.38 & $1,07,94,896$ & 1.000 & $1,07,94,896$ \\
\hline (0) 2011 & Tack Coat & $125,464 \mathrm{~m}^{2}$ & 41.14 & $51,61,618$ & 1.000 & $51,61,618$ \\
\hline (0) 2011 & 2"AC Aggregate & $14,405 \mathrm{~T}$ & 5617.3 & $8,09,17,207$ & 1.000 & $8,09,17,207$ \\
\hline (0) 2011 & Tack coat & $125,464 \mathrm{~m}^{2}$ & 41.14 & $51,61,618$ & 1.000 & $51,61,618$ \\
\hline (0) 2011 & 2" AC wearing & $15,010 \mathrm{~T}$ & 5938.3 & $8,91,33,883$ & 1.000 & $8,91,33,883$ \\
\hline (08) 2019 & Fog seal & $125,464 \mathrm{~m}^{2}$ & 95.14 & $1,19,36,645$ & 0.730 & $87,13,751$ \\
\hline (11) 2022 & Crack seal & $1274 \mathrm{~m}$ & 198 & $2,52,252$ & 0.650 & $1,63,964$ \\
\hline (14) 2025 & Tack Coat & $125,464 \mathrm{~m}^{2}$ & 41.14 & $51,61,618$ & 0.577 & $29,78,254$ \\
\hline (14) 2025 & $2 "$ AC overlay & 15,010 Ton & 5938.3 & $8,91,33,883$ & 0.577 & $5,14,30,250$ \\
\hline (19) 2030 & Fog Seal & $125,464 \mathrm{~m}^{2}$ & 95.14 & $1,19,36,645$ & 0.475 & $56,69,906$ \\
\hline \multicolumn{2}{|c|}{$\begin{array}{l}\text { Sub Total } \\
\text { Less Salvage Value } \\
\text { Net Present Worth }\end{array}$} & & & $3,56,53,553$ & 0.456 & $\begin{array}{l}26,01,25,347 \\
1,62,58,021 \\
\text { 243.87 Million PKR }\end{array}$ \\
\hline
\end{tabular}

Salvage Value $=($ Remaining service life of last rehabilitation treatment $/$ Expected Life of Rehabilitation Treatment $) \times$ cost; Expected Life of $2 "$ AC Overlay in all alternatives $=10$ years. Remaining service Life after 20 th year $=4$ years

performed during the subsequent years is shown which indicates that from year 1997 to year 2007 no preventive maintenance was carried out, despite the appearance of cracks in 2004. This led to the continuous drop in the condition level, which ultimately fell below the minimum acceptable level in year 2007. Instead of rehabilitation with 4" thick overlay, routine maintenance (seal coat) was conducted. Then after a lapse of just one year (i.e. in 2008) again routine maintenance (crack seal) was carried out. The condition level continued to deteriorate and finally in 2011, agency resorted to reconstruction. In order to determine the optimal M\&R activity profiles, agencies must be able to predict the performance trends and future consequences of the various preservation scenarios. In the above presented case study, had the routine maintenance treatment been applied before the crack appeared i.e. in 2002, it would have maintained the condition level at an acceptable service level for considerable period and enhanced the pavement life (Tables 2, 3, 4 and 5).

Assuming the proposed APMS was adopted and the overall M\&R strategy scenario is considered for the case study of runway (Fig. 6). The sample feasible alternatives (rehabilitation) in year 2011 in addition to routine maintenance could include:

- Perform patching and apply complete 2" thick overlay.

- Perform milling and replace the keel (central) portion with 2 " thick overlay.

- Replacement of 4 " thick AC in two lifts.

Table 5 Net Present Worth of Sample Feasible M\&R Alternatives (d) Re-construction of Complete Runway

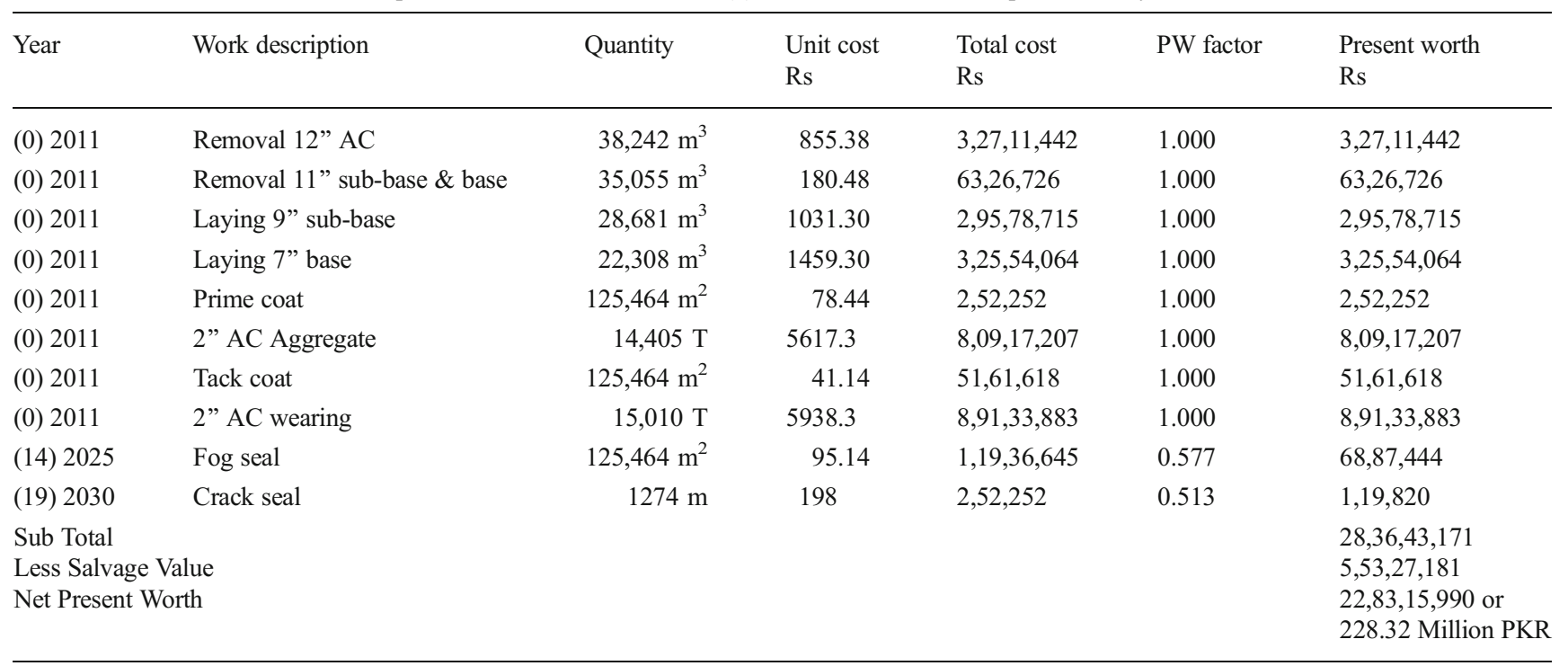


- Re-construction of runway pavement with 9" thick subbase, 7" thick base course (WBM) \& 4" AC in two lifts.

After determining the numerous feasible M\&R alternatives and their respective treatments service lives [5], life cycle cost analysis of each alternative is carried out to determine the most cost effective M\&R strategy. Economic analysis period of 20 years is selected as per FAA pavement design practice with year 2011 as the initial year. Also the analysis period for the first alternative gives a salvage value of zero at 20 years; therefore the same is applied to all other alternatives (ARA [5]). The discount rate 'ir' of $4 \%$ is used on average. M\&R
Fig. 7 Activity profiles of sample feasible M\&R alternatives. a Activity profile alternative No. 1: perform patching and apply complete 2 " thick overlay. b Activity profile alternative No. 2: milling and replace the keel portion with 2" thick overlay c Activity profile alternative No. 3: replacement with 4" thick AC in two lifts. d Activity Profile Alternative No. 4: re-construction of runway pavement (actually applied)

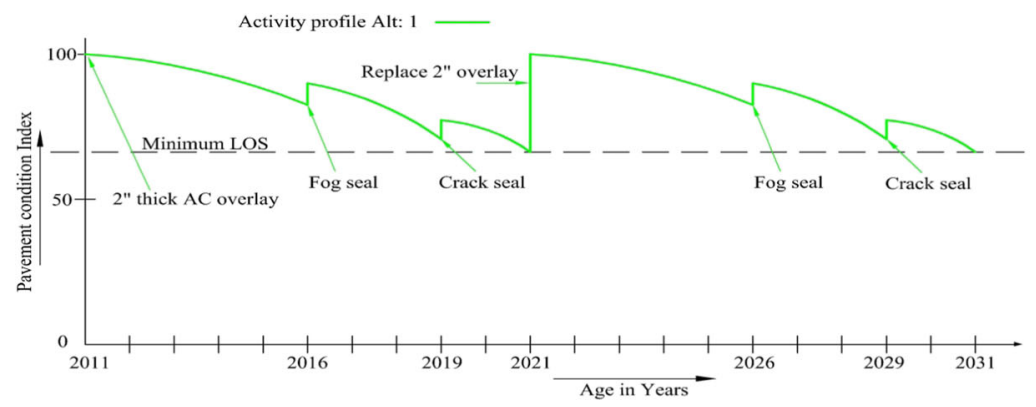

(a) Activity profile alternative No. 1: perform patching and apply complete 2" thick overlay.

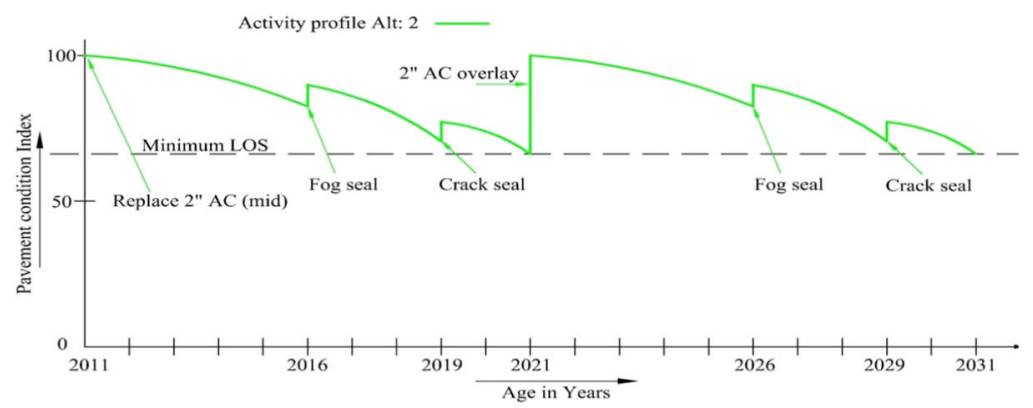

(b) Activity profile alternative No. 2: milling and replace the keel portion with 2" thick overlay

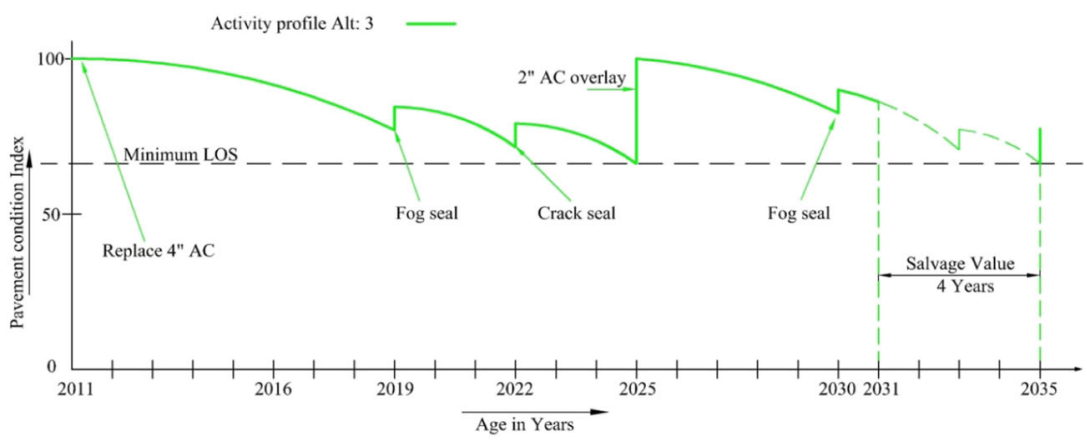

(c) Activity profile alternative No. 3: replacement with 4" thick AC in two lifts.

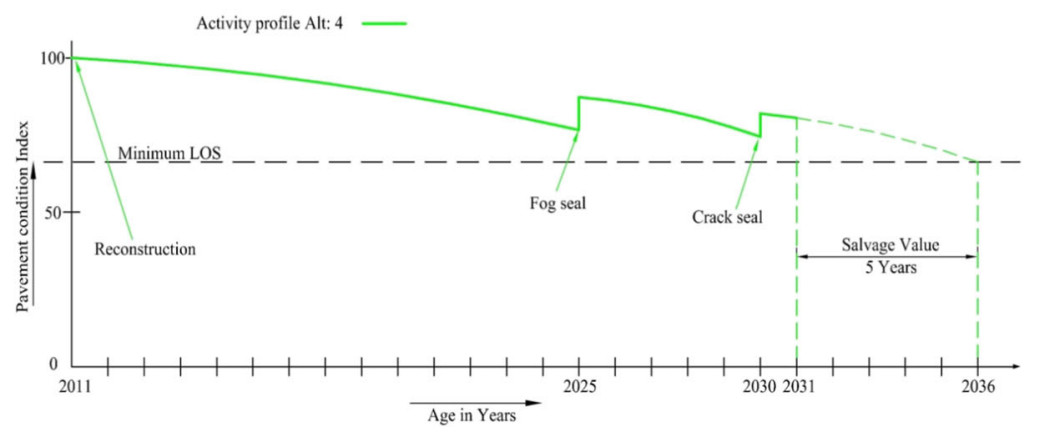

(d) Activity Profile Alternative No. 4: re-construction of runway pavement (actually applied). 
costs, routine maintenance cost and the salvage value are included whereas drainage cost, other user costs remain constant for all alternatives and hence are not considered in the LCCA. Currency used is Pak rupees and rates are taken from local standard schedule of rates (PICC [31]). In the absence of historical airfield pavement distress data/ evaluation, activity profiles of sample (representative but not exhaustive) feasible M\&R alternatives are presented (Fig. 7) which are based on historical record available in the literature (ARA [5]; ACRP [21]) whereas in effect, it should be based upon treatment specific performance models proposed to be developed in the study framework [Eq. (3)].

Cost-effectiveness (CE) index is calculated using Eq. (6) in order to determine the cost-effectiveness of each M\&R alternative. As discussed above, area under the profile curve for each M\&R strategy is calculated, representing the life cycle benefit of each M\&R strategy. In the presence of posttreatment performance models, it could be simply calculated using Eq. (4). Calculated benefits and costs for each alternative are then incorporated in Eq. (6) to get CE index. Table 6 shows the $C E$ index for each M\&R strategy. It is observed that Alternative 2 (Replacement of 2" thick AC Overlay of keel section) with the lowest NPW, has the highest CE index. Thus Alternative 2 is considered as the most feasible M\&R strategy satisfying both criteria, i.e. cost only and cost-effectiveness. In other words, it entails minimum cost while yielding maximum possible corresponding benefit (pavement performance).

The proposed methodology was applied to check the stepwise procedure of the proposed framework given certain feasible M\&R alternatives. LCCA of each of the proposed alternative is carried out for cost effectiveness using analysis period of 20 years, discount rate of $4 \%$, overlay life of 10 years and MES schedule of rates, The LCCA results revealed that the reconstruction was the most expensive alternative, whereas the replacement of mid-section (keel) was the most cost effective alternative

\section{Implementation plan and conclusions}

A gradual stepwise implementation is a more viable solution for many management systems. This include starting with specific group of pavements at airfield such as pavements having a high rate of deterioration, requiring immediate attention or runways and major airfields followed by other pavements. The implementation of proposed APMS includes studying, reviewing and applying existing and exploring new methods and procedures for better understanding and description of airfield pavements. The correlation among all factors that influence airfield pavement performance such as load, environment to develop performance models, selection of feasible M\&R alternatives, economics, construction and maintenance practices, management systems and their components must also be considered for implementing APMS. It is important that all stakeholders (potential users/ agencies) of the APMS are identified depending upon their individual needs so that everyone is satisfied with the end product. These potential users of an APMS differ depending on the implementing agency i.e., individual airfield, agency or branch of the military/ air force e.g. civil aviation authority maintains its pavements keeping in view the commercial aspects whereas air force would maintain and consider it as per its operational requirement. The level of maintenance and the timing for closure of operating surfaces is of extreme importance to the operating and managing agencies. The decision for adoption of particular M\&R treatment rests with the agency concerned depending on their operational requirements. Finally agencies responsible for managing the airfield pavements have to allocate sufficient funds and adequate manpower to implement and sustain the APMS in order to ensure that it remains productive in the long term.

As one of the important assets in a country, airport networks need to be sustained and maintained in an adequate condition. The proposed APMS is perhaps the most beneficial application for pavement managers and decision makers as it follows a methodical plan in finding strategies for providing and maintaining pavements in a serviceable and safe condition at the most cost-effective way. The developed pavement management process provides systematic and objective procedures for maintaining the inventory of pavement infrastructure, monitoring pavement performance, selecting the right treatment for the right pavement at the right time, planning and budgeting of airfield pavement preservation activities and evaluating the cost-effectiveness of past pavement preservation actions. For

Table 6 Cost-effectiveness based comparison of M\&R alternatives

\begin{tabular}{lllll}
\hline S. No. & Description of alternative & $\begin{array}{l}\text { Life cycle cost } \\
\text { NPW } \\
\text { (Mn PKR) }\end{array}$ & $\begin{array}{l}\text { Life cycle benefit } \\
\text { AUC } \\
\text { (PCI-Years) }\end{array}$ & $\begin{array}{l}\text { CE index } \\
\text { (PCI-Year/ Mn PKR) }\end{array}$ \\
\hline 1. & Joint Filling, Patching and Laying of 2" thick overlay & 178.62 & 360 & 2.02 \\
2. & Replacement of 2" thick AC Overlay of keel section & 113.74 & 390 & $\mathbf{3 . 4 3}$ \\
3. & Replacement of complete 4" thick AC Overlay & 243.87 & 403 & 1.65 \\
4. & Re-construction of complete Runway & 228.32 & 415 & 1.81 \\
\hline
\end{tabular}


agencies seeking to replicate the study for their airfield pavement management system, an important recommendation is that the contract details of all the treatment projects be examined carefully to ensure that non pavement activities have no influence on the chosen performance indicator/ measure of effectiveness, otherwise, the treatment costs will be unduly high, yielding lower cost effectiveness. Also, the costeffectiveness analysis in the present study hinges heavily on performance models which, in turn, depend on accuracy of data on the pavement performance of the treated pavement and selected performance indicators.

Acknowledgments and Disclaimer The authors gratefully acknowledge the contribution of local airfield managing agencies officials and staff in sharing valuable inputs and data/ document sharing for this research study. The contents of this research study reflect the views and opinion of the authors and do not necessarily express, present or reflect the official view, position, slant or policies of the airfield agencies. This is purely an academic work and does not constitute a standard, specification, regulation, principle, reference or criterion. Nevertheless, every effort has been made to make this research study as complete and as accurate as possible.

Open Access This article is distributed under the terms of the Creative Commons Attribution 4.0 International License (http:// creativecommons.org/licenses/by/4.0/), which permits unrestricted use, distribution, and reproduction in any medium, provided you give appropriate credit to the original author(s) and the source, provide a link to the Creative Commons license, and indicate if changes were made.

\section{References}

1. Haas R, Hudson WR, Zaniewski J (1994) Modern pavement management. Krieger Publishing Company, Malabar

2. Federal Aviation Administration (FAA) (2007) Guidelines and procedures for maintenance of airport pavements. Advisory CircularNo.AC 150/5380-6B, September 2007

3. MicroPAVER. "U.S. Army Construction Engineering Laboratory (USA-CERL), Engineering and Resources Development Centre", Champaign, IL, 2003

4. McNerney MT, Harrison R (1995) Enhanced pavement management systems for airports: a Full cost analysis of operational impacts, Conference Proceedings, 1995,pp. 496-510

5. Applied Research Associates (ARA) (2011) Life cycle cost analysis for airport pavements". Airfield Asphalt Pavement Technology Program (AAPTP), 277 Technology ParkwayAuburn, AL

6. Broten M, Wade M (2004) How to sustain a pavement management system at a commercial-service airport," Proceedings of the 6th International Conference on Managing Pavements, Queensland, Australia, 2004

7. Michigan Department of Transportation, Capital Preventive Maintenance Program Guidelines, Maintenance Division, Michigan Department of Transportation, Lansing, MI, 1999

8. Minnesota Department of Transportation, Pavement Preventive Maintenance Program Guidelines, Office of Materials and Road Research, Minnesota Department of Transportation, St. Paul, 2001

9. Ohio Department of Transportation (2001) Pavement Preventive Maintenance Program Guidelines", The Office of Pavement Engineering, Ohio Department of Transportation, Columbus, 2001
10. California Department of Transportation, "Maintenance Technical Advisory Guide" Volume-Flexible Pavement Preservation, 2nd ed., Division of Maintenance, Office of Pavement Preservation, California Department of Transportation, Sacramento, 2008

11. U.S. Department of Defence (US DoD) (2004). Unified Facilities Criteria on Pavement Maintenance Management, UFC 3-270, U.S. Department of Defense, Washington

12. Ismail N, Ismail A, Rahmat OK (2009) Development of expert system for airport pavement maintenance and rehabilitation. Eur J Sci Res ISSN 1450-216X Vol.35 No.1, 2009, pp. 121-129

13. Baladi GY, Novak EC Jr, Kuo WH (1992) pavement condition index remaining service life". Pavement management implementation. In: Holt FB, Gramling WL (eds) STP 1121. American Society for Testing and Material, Philadelphia, PA, pp 63-90

14. Lee H (1992) Standardization of Distress Measurements for the Network-Level Pavement Management Systems".Pavement Management Implementation. In: Holt FB, Gramling WL (eds) STP 1121. American Society for Testing and Material, Philadelphia, pp 424-436

15. Monismith CL (1978) Considerations in airport pavement management". Transportation Research Board, Special Report 175, 1978,pp. 10-34

16. Hudson WR, Uddin W (1987) Future pavement evaluation technologies: prospects and opportunities". Presented atSecond North American Conf. on Managing Pavements, Toronto, Canada, 1987

17. Lytton RL (1987) Concepts of pavement performance prediction and modeling". Presented atSecond North American Conf. on Managing Pavements, Toronto, Canada, 1987

18. Butt AA (1991) Application of markov process to pavement management systems at the network level".Ph.D. Dissertation, Department of Civil Engineering, University of Illinois at UrbanaChampaign, IL, 1991

19. Rada GR, Schwartz CW, Witczak MW, Rabinow SD (1992) Integrated pavement management system for kennedy international airport. J Transp Eng 118:666-685

20. Zaniewski J (1991) Unified methodology for airport pavement analysis and design". Technical Report, Federal Aviation Administration". Research and Development Service, Washington, DC.,1991

21. Airport Cooperative Research Program (ACRP) (2011) "Common airport pavement maintenance practices. Transportation Research Board, A Synthesis of Airport Practice (Synthesis No. 22), Washington, D.C

22. Shahin MY (2002) Pavement management for airport, roads and parking lots. Springer, Second Edition

23. Irfan M, Khurshid MB, Bai Q, Labi S, Morin TL (2012) Establishing optimal project -level strategies for pavement maintenance \& rehabilitation - a framework and case study. Taylor \& Francis's J Eng Optim 44(5):565-589

24. Wade M, Peshkin D, Smith K, Yu HT (2007) Estimating remaining life of airfield pavements, Proceedings of the 27thInternational Air Transportation Conference, Advancing Airfield Pavements, American Society of Civil Engineers, VA, 2007

25. Khurshid MB, Irfan M, Labi S (2011) Optimal performance threshold determination for highway asset interventions: analytical framework and application. J Transp Eng 137(2):128-139

26. Lamptey G (2004) Optimal scheduling of pavement preventive maintenance using life cycle cost analysis, M.S. Thesis, Purdue University, West Lafayette, IN, 2004

27. Irfan M, Khurshid MB, Labi S, Flora W (2009) Evaluating the cost-effectiveness of flexible rehabilitation treatments using different performance criteria. ASCE J Transp Eng 135(10):753763 
28. Zimmerman KA, Smith KD, Grogg MG (2010) Applying economic concepts from an LCCA to a Pavement Management Analysis," 89thAnnual Meeting of the Transportation Research Board, Washington, Paper No. 00-1351, D.C., 2010

29. Peshkin DG, Hoerner TE, Zimmerman, KA (2004) Optimal timing of pavement preventive maintenance treatment applications, NCHR P, Rep. 523, TRB, Washington, D.C., 2004
30. Labi S, Sinha KC (2005) Life-Cycle Evaluation of Flexible Pavement Preventive Maintenance. ASCE J Transp Eng 131(10): 741-751

31. Pakistan Institute of Costs and Contracts (PICC). Schedule of Rates (SoR) for basic and composite items. PICC House, 275-A, New Muslim Town, Lahore, (available http://picc.org.pk/sorSearch. aspx. Accessed 7 Mar 2011 